\title{
Aspectos da governança local: inserção internacional das cidades através de redes de cidades
}

Graziela C. Vital*

\begin{abstract}
Resumo
Os efeitos dos processos da globalização ocorridos nas últimas décadas impulsionaram o debate acerca do papel das cidades em um contexto de aprofundamento da competição por recursos, acesso a investimentos estrangeiros, tecnologia, entre outros aspectos. Destaca-se neste debate a intensificação da inserção internacional das cidades como estratégia de criação de novos padrões de governança local. Este artigo argumentará que um dos mecanismos de inserção internacional é a formação de redes de cidades, que despontam como instrumentos de organização para promoção da integração e melhoria das políticas públicas das cidades, através do desenvolvimento de acordos e programas. Neste contexto, o artigo apresentará a Rede de Mercocidades em um estudo de caso.

Palavras-chave: Governança, globalização, redes de cidades, Mercocidades.
\end{abstract}

\section{Introdução}

Os efeitos dos processos da globalização ocorridos nas últimas décadas impulsionou o debate acerca do papel das cidades em um contexto de aprofundamento da competição por recursos, acesso a investimentos estrangeiros, entre outros aspectos. Tais fatores têm levado a importantes mudanças no oferecimento de serviços públicos e na estruturação da vida nos centros urbanos. Se por um lado há uma transformação na estrutura produtiva das cidades, gerando processos de exclusão social, segregação urbana, desigualdade social, entre outros, há por outro lado a busca por novas formas de governança local, impulsionadas pela interação formal e informal dos vários atores nacionais, subnacionais e não estatais.

Neste contexto de expansão da ideia de governança, ocorre o fortalecimento de outros agentes e atores políticos, econômicos e sociais, nos quais também se incluem os governos locais ou subnacionais. As estratégias de inserção internacional destes entes subnacionais tornam-se instrumentos de governança local, provocando

\footnotetext{
* Mestre pela University of Waterloo, Canadá, onde foi professora assistente, é hoje doutoranda em Relações Internacionais pela Universidade de São Paulo e coordenadora do curso de Administração da Universidade Cidade de São Paulo. Formada em Administração pela Universidade Presbiteriana Mackenzie e em Ciência Política pela University of Calgary, Canadá. Email: grazievital@hotmail.com.
} 
impactos na oferta de políticas públicas em áreas sensíveis à vida urbana, tais como habitação, segurança, pobreza, entre outros, que são diretamente ligados aos efeitos provocados pelos processos de globalização.

Um dos mecanismos possíveis de inserção internacional e foco deste artigo é a formação de redes de cidades. Neste contexto, o objetivo é analisar a questão da inserção internacional das cidades sob a luz dos princípios de governança local, e argumentar que as redes de cidades despontam como instrumentos de organização para promoção da integração e melhoria das políticas públicas das cidades, através do desenvolvimento de acordos e programas de interesse mútuos.

Este artigo está dividido em três partes: um breve levantamento teórico sobre globalização e governança local; uma contextualização teórica sobre a inserção internacional das cidades e uma análise empírica de uma importante da Rede de Mercocidades.

\section{A globalização quanto ao seu caráter global e local}

Não se pode afirmar que exista uma definição para globalização que seja universalmente aceita (Held e McGrew, 2000), mas é possível reconhecer que processos globalizantes permeiam a história do desenvolvimento humano desde as primeiras civilizações existentes. Os processos migratórios ocorridos ao longo da história indicam a existência de movimentos de expansão e conquista de novos povos e territórios ao longo dos séculos, intercalando períodos de maior ou menor intensidade expansionista.

Em uma definição amplamente utilizada na literatura, Held (1997, p.3) sintetiza o conceito de globalização da seguinte maneira:

Globalization is best understood as a spatial phenomenon, lying on a continuum with 'the local' at one end and 'the global' at the other. It denotes a shift in the spatial form of human organisation and activity to transcontinental or interregional patterns of activity, interaction and the exercise of power. [. . .] Globalization today implies at least two distinct phenomena. First, it suggests that many chains of political, economic and social activity are becoming interregional in scope and, secondly, it suggests that there has been an intensification of levels of interaction and interconnectedness within and between states and societies. 
A descrição acima ressalta como aspecto central da globalização seu caráter ao mesmo tempo global e local, e a crescente compreensão da supranacionalidade como fator preponderante das relações entre os atores políticos, econômicos e sociais contemporâneos. Held e McGrew (2000) identificam, em consonância com os aspectos históricos da globalização, a existência de uma globalização contemporânea, que indica um momento atual de transformações na organização socioeconômica, nos princípios territoriais e nas relações de poder, e que se diferencia dos processos ocorridos anteriormente na história humana pela dimensão, intensidade e forma com que a globalização contemporânea ocorre. Muitos estudiosos argumentam que o período de maior globalização ocorreu no período anterior à Primeira Guerra Mundial, além de pontuarem a existência de períodos de grande expansão territorial, notadamente nos anos 1500, com as grandes expansões marítimas.

Na globalização contemporânea, percebe-se a existência de novos padrões e sistemas de interconexões, que se organizam e se reproduzem de maneiras diferentes de períodos anteriores. Tais conexões ocorrem de maneira mais intensa e profunda, ressaltando uma nova configuração geográfica, marcada por uma intensificação nos fluxos de comércio e finanças entre as grandes potencias na economia mundial, ao mesmo tempo provocando transformações nas configurações de relações de poder inter-regionais (Held e McGrew, 2000). Neste sentido, Hardt e Negri (2004, p. xiii) argumentam que globalização contemporânea possui duas faces:

\footnotetext{
On one face, Empire spreads globally its network of hierarchies and divisions that maintain order through new mechanisms of control and constant conflict. Globalization, however, is also the creation of new circuits of cooperation and collaboration that stretch across nations and continents and allow an unlimited number of encounters. This second face of globalization is not a matter of everyone in the world becoming the same; rather it provides the possibility that, while remaining different, we discover the commonality that enables us to communicate and act together.
}

Ao evocar o Império, Hardt e Negri reinterpretam o conceito de Imperialismo, no contexto da globalização contemporânea, não em seu aspecto tradicional de subjugação de povos e territórios, mas sim no sentido de indicar a criação de uma 
nova ordem global, marcada pela formação de sistemas globais e locais de regulações (principalmente em seus aspectos econômicos) que não possuem fronteiras (Held e McGrew, 2000).

Para Modelski et al (2008), o conceito de globalização deve ser compreendido como um processo, indicando uma sequencia de eventos ao longo de um determinado período de tempo, e que apesar de ser frequentemente associado à questões econômicas, seu escopo é multidimensional, com um forte componente histórico e claramente transformacional. Em consonância com a concepção da globalização como uma série de processos que tem transformado o mundo desde a década de 1970, Mittelman (2001) argumenta que tais processos produzem relações hierárquicas, especialmente no que se refere às relações de poder e produção de trabalho e capital. Nesta concepção, o autor ressalta alguns dos aspectos vexatórios da globalização, quanto à questão de controle, autonomia e agencia. Para Mittelman, a combinação de da interconexão entre atores globais, regionais, nacionais e locais leva ao questionamento sobre quem são os atores que influenciam a formação dos interesses globais, se há meios de governança abrangentes ou excludentes, quem ganha e quem perde com os processos da globalização recente, entre outros aspectos.

Para Scholte (2000, p. 8), a globalização deve ser compreendida como uma reconfiguração geográfica marcada pelo crescimento das conexões supraterritoriais. 0 autor reconhece o longo processo histórico pelo qual a globalização pode ser compreendida, porém ressalta que existe em ação um processo mais recente, datado da metade do século $X X$, em que os processos globalizantes empreenderam um novo ritmo de crescimento, estreitamente ligado com o desenvolvimento de novas estruturas produtivas, formas de governança, identidade e difusão do conhecimento. Tais mudanças impulsionaram transformações quanto à compreensão de conceitos fundamentais sobre territorialidade, soberania, democracia, igualdade social, política e econômica, tanto em seus aspectos positivos quanto negativos (ainda que o autor não associe aspectos negativos à ideia de globalização em si, mas sim à adoção de das políticas públicas inspiradas nos ideais neoliberais largamente existentes na segunda metade do século $X X)$. 
A questão da territorialidade, assim como da economia, são alguns dos aspectos mais discutidos nas teorias da globalização. Para Brenner (2004, p. 6), é preciso compreender o fenômeno da globalização a partir da proposição de que a forma territorial do estado, concebida ao longo dos séculos, tem sido sistematicamente desafiada e transformada em períodos recentes, gerando constantes embates sociais, econômicos e políticos direcionados à reorganização da geografia institucional do capitalismo, que prolifera para todas as escalas espaciais. Ainda segundo o autor, a reorganização do espaço em termos políticos e econômicos indica a existência de três tendências mundiais distintas: (i) uma maior integração econômica global, em que os fluxos de investimentos possuem um caráter supranacional e global; (ii) um renascimento da importância do "local e do regional", em que atores subnacionais representam os motores da economia global, por serem os detentores de fato da capacidade inovadora e tecnológica, dos bens econômicos e sociais, da mão de obra especializada, entre outros; e finalmente (iii) uma consolidação de novas estruturas e instituições supranacionais e entre fronteiras, verificadas especialmente nas redes formadas tanto por governos centrais, quanto por governos subnacionais e locais.

Dentre as várias definições sobre a globalização, um dos aspectos constantemente atribuídos é a ideia de processo de reformulação da espacialidade focada no estado-nação para uma lógica não-territorial, no que tange a organização política do mundo (Stransbjerg, 2010). Tal argumento não significa o desaparecimento do estado, porém indica mudanças na organização política mundial, que trazem implicações na organização econômica, politica e social aos governos locais, os quais buscam estratégias para adaptar-se às novas configurações globais e à novas demandas por modelos de governança. 


\section{Conceitos de governança}

Rosenau e Czempiel (1992) foram os primeiros autores a oferecerem uma definição abrangente e desafiadora para o conceito de governança. Abrangente por que situa a o conceito em um cenário onde os poderes hegemônicos estão em declínio e as fronteiras estão desaparecendo, e desafiadora por propor que as cidades têm questionado as autoridades tradicionais (governos centrais). Rosenau e Czempiel argumentam que as alianças militares têm perdido sua viabilidade, e que novas formas de governança voltadas às questões socioeconômicas têm surgido a partir deste cenário. Para os autores, a ideia de governança se refere a atividades apoiadas por objetivos em comum que podem ou não surgir de responsabilidades legais estabelecidas, e não necessitam do suporte da estrutura formal de governo. Portanto, a ideia de governança é distinta da concepção de governo. Um dos argumentos para essa afirmação reside na afirmação de Rosenau e Czempiel de que a ideia de governança está relacionada "a instituições governamentais, porém também pressupõem mecanismos não governamentais informais, pelos quais as pessoas e organizações em geral se organizam para satisfazer suas necessidades e vontades" ( $p$. $5)$.

Em uma perspectiva similar, Stoker (1998) afirma que governança deve ser compreendida como uma parte da atividade humana interessada em criar as condições para uma ação coletiva ordenada e fundamentada em regras, que independe da ação do governo. Para o autor, o que diferencia governança de governo são os diferentes processos relacionados a um e outro. Em outras palavras, Stoker $(1998$, p. 17) afirma que governance refers to the development of governing styles in which boundaries between and within public and private sectors have become blurred. The essence of governance is its focus on governing mechanisms which do not rest on recourse to the authority and sanctions of government.

Entretanto, em uma análise crítica sobre o debate acerca do conceito de governança, Stoker argumenta que o termo é utilizado para encobrir cortes de gastos do governo, e esconde em sua origem os efeitos das medidas neoliberais de privatização e terceirização dos serviços públicos para agentes do mercado. Tal 
perspectiva é compartilhada por diversos autores (Les Galés, 2011; Kazepov, 2005; Harding, 1997, Leitner e Sheppard, 2002), que reforçam a ideia de que governança está intrinsecamente ligada ao processo de globalização e integração de mercados, que leva a novas formas e padrões de competição econômica entre cidades e regiões.

Porém, cabe ressaltar, para efeito de contextualização do termo globalização quanto aos seus efeitos sobre cidades e regiões, a afirmação de Milani e Ribeiro (2011, p. 1), que argumenta que:

\begin{abstract}
Globalization is not merely a competition for market shares and well-timed economic growth initiatives; neither is it just a matter of trade opportunities and liberalization. Globalization has also evolved into a social and political struggle for defining cultural values and political identities (Benhabib, 2006; Milani \& Laniado, 2007), having major consequences for the internationalization of politics through the increasing development of transnational actors, networks and institutions (Ianni, 2002; Santos, Souza, Scarlato, \& Arroyo, 1994). Subnational entities, such as provinces, federatestates and municipalities also benefit from various political opportunity structures that have emerged from globalization processes.
\end{abstract}

Ainda que seja de extrema relevância contextualizar a questão da governança criticamente quanto à sua relação aos aspectos negativos do processo de globalização e das desigualdades decorrentes deste processo, neste artigo a ideia de governança será analisada quanto à formação de estruturas que surgem a partir da intensificação das ações dos governos subnacionais, em especial as municipalidades, na competição por atração de recursos e ganhos de autonomia em relação ao Estado-nação.

Desta forma, importa conceitualizar a ideia de governança quanto às suas especificidades no nível local. Sellers e Kwak (2011) sugerem que para a elaboração efetiva de políticas públicas no nível nacional é fundamental que haja uma interação entre os níveis mais altos de governo com as estruturas de governança local.

Os níveis locais de governo são essenciais para a compreensão dos mecanismos efetivos de governança local. Para Rhodes (1996) é preciso analisar o mundo no qual as redes competem com os mercados e as burocracias como os meios apropriados para a solução de problemas e a realização eficaz de serviços públicos. O autor afirma que governança se refere a "self-organizing, interorganizational networks and these 
networks complement markets and hierarchies as governing structures for authoritatively allocating resources and exercising control and co-ordination" (Rhodes, 1996, p.21) Ainda que Rhodes tenha escrito tal afirmação ao pesquisar os sistemas de governo de Westminster e Whitehall, é possível expandir o conceito de redes no contexto da governança local para formas de interação entre cidades. O autor afirma que as redes são uma forma generalizada de coordenação social e que a administração de canais Interorganizacionais são mecanismos de ação tanto de governos quanto do setor privado, e não raramente uma combinação da ação de vários atores políticos e sociais.

As cidades são, portanto, centros nodais desta interação em rede, que se intensifica á partir dos anos 90, conforme o processo de globalização se acentua, compelindo cidades a adotarem modelos de governança local que possibilitassem uma maior inserção internacional, a fim de obter ganhos econômicos e sociais compatíveis com as crescentes demandas por serviços públicos. Castells $(2005$, p. 152) enfatiza que:

Durante a década de 90 houve um processo acelerado para internacionalizar a produção, distribuição e gestão dos bens e serviços. Este processo compreendia três aspectos inter-relacionados: o crescimento do investimento direto estrangeiro, o papel decisivo das multinacionais como produtoras na economia mundial e a formação de redes de produção internacionais.

Pode-se afirmar, portanto, que as transformações políticas, econômicas e sociais ocorridas na década de 90 provocaram mudanças na forma pelas quais as cidades tiveram que se reorganizar e reestruturar para responder aos novos cenários de maior competição por recursos, capital, mão de obra qualificada, entre outros. Surge como consequência movimentos de intensificação da inserção internacional das cidades através de diversos mecanismos de inserção internacional, dentre os quais, neste artigo, será ressaltada a participação em redes de cidades. 


\section{Inserção internacional das cidades}

As cidades refletem os valores, cultura, e expectativas de seus habitantes, expressos na arquitetura urbana, nos marcos e monumentos históricos, na forma como as pessoas ocupam o espaço público, e até mesmo na forma como o transito de veículos e pessoas se desenvolvem no dia-a-dia (Bell e De-Shalit, 2011). Em uma época marcada pelos efeitos dos processos da globalização, as cidades tem se tornado cada vez mais atores econômicos, políticos e sociais relevantes e o crescimento populacional e a crescente urbanização da maior parte dos países do mundo tem suscitado a necessidade de compreendermos as novas formas de governança destas cidades.

Cidades são consideradas, tanto do ponto de vista econômico quanto político e social, como "espaços de fluxo" (Castells, 2000), ou seja, locais por onde os processos da globalização ocorrem. Os "espaços de fluxo" são formados por intersecções (nodes) e redes de conexões, pelos quais circulam informações, tecnologia, trocas de práticas e tomadas de decisões, entre outros. Castells identifica as cidades como sendo os locais propícios a tais fluxos, pois as cidades representam os locais onde pessoas e organizações reafirmam sua cultura, experiências e demandas.

Segundo o autor, os "espaços de fluxos" se desenvolvem em três níveis: infraestrutura, relações sociais e relações da elite. De acordo com esta classificação, a globalização leva à formação de centros que desempenham papeis de comando e controle (muitas vezes representadas por cidades que possuam expressivo poder de atração de capital e sedie multinacionais relevantes à economia global). No nível da infraestrutura, encontra-se a estrutura tecnológica que permite um constante aprimoramento das redes de comunicação (fator fundamental no processo de obtenção de vantagens competitivas nos processos da globalização contemporânea). O segundo nível refere-se à capacidade de uma localidade em ser reconhecida como um local de intersecção (nodes e hubs) relevante, capaz de atrair investimentos e influenciar decisões globais. Por fim, o terceiro nível refere-se à formação e 
participação das cidades em redes compartilhadas, que desponta como um dos possíveis instrumentos de inserção internacional das cidades.

Para Aldecoa e Keating (1999) o processo de globalização impôs uma reestruturação política, social e econômica de países e regiões, promovendo uma maior mobilização de pessoas, recursos e capital em escala global, com impacto nas políticas públicas locais. Os autores também argumentam que esse processo impulsiona uma relação de competição entre regiões, províncias, estados e cidades. Desta forma, a expansão dos limites de atuação das cidades faz com que estas procurem criar instrumentos de multiplicação e diversificação de vínculos com outros atores subnacionais e não estatais. A criação então de estruturas e instituições específicas, voltadas à intensificação dessas relações entre fronteiras sinaliza que:

\footnotetext{
a criação de uma estrutura institucional específica de relações internacionais no aparato administrativo de um governo subnacional denota não o começo de uma atuação internacional, mas sua intensificação e a vontade de agir mais organizadamente do que até então (Salomón e Nunes, 2007, p.25).
}

De acordo com Kjeld Jakobsen, ex-secretário municipal de Relações Internacionais de São Paulo de 2003 a 2004, “o fato de os municípios fortalecerem sua posição como esfera do Estado e ter demandas concretas que não são devidamente atendidas pelos governos federais reforça a procura por inserção internacional dos governos municipais." (apud Rodrigues et al, 2009).

Desta forma, em uma perspectiva de intensificação da inserção internacional das cidades, pode-se argumentar que também se intensificam as iniciativas de formação de redes de cidades, pois estas redes podem ser compreendidas como mecanismos que possibilitam o compartilhamento de experiências de governança local.

\section{Redes de cidades}

O histórico da formação de redes de cidades está profundamente relacionado à própria reestruturação produtiva que teve início na década de 70 . Com a reestruturação produtiva, houve uma intensificação da externalização econômica, em 
que fluxos de capital, mão de obra, locais de produção, entre outros, sofreram transformações fundamentais. De acordo com Bagnasco e Le Galés (2000) o processo de reestruturação produtiva provocou um movimento de abertura dos espaços regionais e nacionais, envolvendo governo, mercado e sociedade civil. Também intensificou a diluição de fronteiras, aprofundando a integração econômica de mercados e envolvendo a esfera pública, consequentemente gerando demandas por diferentes formas de organização política e social não confinada à esfera nacional. Os autores ressaltam que essas transformações provocaram um fortalecimento do papel das cidades, afirmando que:

[T]he reinforcement of social and political organisation in certain cities, which the concept of governance is an attempt to explain, is different from the political as defined in terms of legal and rational domination. It is much more a case of the mobilisation of social groups, institutions and public and private actors forming alliances and collective projects with the twofold aim of attempting to adapt to economic change and of counterbalancing somewhat - or even protecting themselves from - the effects of the market (Bagnasco e Le Galés, p. 25, 2000).

Como consequência das transformações econômicas das últimas décadas, pode-se argumentar que um dos meios de contrabalancear os efeitos negativos da globalização dos mercados é a formação de redes de cidades, pois a formação de redes é um tipo de projeto coletivo de compartilhamento de iniciativas e projetos que afetam diretamente a vida nos centros urbanos.

De acordo com Batten (1995) existe um longo histórico de formação de redes de cidades dentro de um mesmo país, que se configuram em conexões de complementaridade de funções, ou seja, cidades que formam relações horizontais e multicentrais. O autor argumenta que redes de cidades se formam a partir da necessidade de se aumentar a cooperação econômica, percebidas nas ações que visam melhorar a infraestrutura de transporte e comunicações entre estas cidades. Entretanto, há iniciativas que tem como prioridade atividades baseada no desenvolvimento do conhecimento, com foco na educação, pesquisa, artes, entre outros. As cidades tornam-se ainda mais relevantes como centros produtores de 
conhecimento e inovação, onde se desenvolvem relações de maior complexidade e interdependência entre os diversos atores que coexistem no âmbito municipal e internacional.

A proliferação de redes de cidades (i.e. World Cities; Sister Cities; Eurocities, Rede de Mercocidades, entre outras) demonstram que cidades de diferentes países e regiões podem compartilhar valores em comum, possibilitando o surgimento de estratégias de cooperação e de boas práticas de gestão pública e urbana (Baycan Levent, Kundak e Gulumser, 2004).

Para Benito del Pozo (1997, p. 130 apud Simões, 2010, p. 20), para se compreender o papel das redes de cidades é importante ressaltar que estas:

(i) permitem que seus membros integrem um sistema de relações superiores; (ii) permitem o acesso a grandes volumes de informação; (iii) consolidam-se como mecanismos de desenvolvimento de política externa; (iv) reforçam as funções de liderança e imagem e (v) contribuem para uma relativa estabilidade de atuações, num ambiente marcado pela mudança contínua.

Leitner e Sheppard (2002) apontam aspectos da dualidade do papel da rede de cidades. Por um lado os autores reconhecem que a formação de redes pode ser um disseminador da agenda neoliberal predominante nos países desenvolvidos, pois estas se utilizam de instituições e estruturas capturadas e replicadoras das estruturas elitistas que excluem a participação efetiva da sociedade civil. Entretanto, ressaltam que a formação de redes de cidades podem na verdade desafiar o status quo, por oferecer uma arena de participação mais autônoma e efetiva para promover políticas públicas mais abrangentes, distanciando-se da lógica de mercado das medidas neoliberais.

Portanto, cabe ressaltar a importância de se analisar exemplos de redes de cidades como instrumento de inserção internacional sob a luz dos princípios de governança local e seus impactos na elaboração de políticas públicas locais. Neste artigo será analisado empiricamente o exemplo da Rede de Mercocidades, que será analisada quanto as principais aspectos da ação coletiva internacional e da interação entre governos nacionais, subnacionais e sociedade civil, e seus impactos nas políticas públicas locais. 


\section{Rede de mercocidades}

A Rede de Mercocidades foi escolhida como estudo de caso deste artigo por representar uma iniciativa que exemplifica a questão da inserção internacional das cidades, ao mesmo tempo em que incorpora os principais aspectos da governança local.

Em 1995 foi celebrada a I Conferência da Rede em Assunção, fruto da iniciativa de 11 prefeitos de países membros do Mercosul $^{1}$, que discutiram durante o seminário "Mercosul: Oportunidades e Desafios para as Cidades" maneiras de se consolidar uma "visão de autêntica cidadania partindo desde as sociedades locais." (MERCOCIDADES, 2012). Desta forma surge a Rede de Mercocidades, uma rede de cooperação horizontal que promove a inserção das cidades membros no processo de integração regional do Mercosul, e cuja importância vem crescendo, tanto em quantidade de membros como em intercâmbio de experiências, bem como quanto ao escopo das áreas temáticas estruturadas para atuação nas políticas públicas locais. Hoje a Rede de Mercocidades abriga 261 cidades, de 9 países da América do Sul.

Segundo os conceitos de governança definidos neste artigo, destaca-se a ideia de que são necessários mecanismos, formais ou informais, efetivos capazes de suprir desejos e necessidades das pessoas e governos locais. De acordo ao art. 2 de seu Estatuto, a Rede de Mercocidades se constitui para, dentre outros objetivos, criar mecanismos de comunicação em redes, entre as cidades, a fim de facilitar o intercâmbio de experiências e informações, bem como ao acesso dos cidadãos aos centros municipais de investigação, desenvolvimento tecnológico e cultural (item III); potencializar os recursos humanos e as experiências administrativas para gestões locais (item V); coordenar a planificação e promoção de ações vinculadas ao crescimento e progresso urbano das cidades (item VI); coordenar projetos e

\footnotetext{
${ }^{1}$ O MERCOSUL é o programa de integração econômica de cinco países da América do Sul. Em sua formação original o bloco era composto por quatro países: Argentina, Brasil, Paraguai e Uruguai, com posterior adesão da Venezuela ao bloco.
} 
desenvolver programas integrados, com o objetivo de facilitar a realização de serviços, e qualificar a infraestrutura urbana (item VII).

Para atingir tais objetivos, a Rede de Mercocidades coloca em seus projetos uma grande ênfase no caráter descentralizado e na participação democrática dos diversos atores envolvidos, em especial agentes da administração pública, organizações da sociedade civil e políticos (Famsi, 2011). Neste mesmo relatório, ressalta-se a concepção das cidades como agentes legítimos que devem atuar na vida politica, econômica e cultural internacional, reforçando o papel dos mecanismos paradiplomáticos para efetiva obtenção das demandas democráticas das cidades.

Sob esse aspecto, a Rede de Mercocidades salienta o caráter pedagógico do processo participativo, e ressalta a importância da construção coletiva das experiências de participação democrática mais representativa das localidades, bem como da região compreendida pelos países do Mercosul. Tais ações representam um aumento no grau de institucionalização da atuação internacional das cidades. O grau de relevância de tais mecanismos institucionais adotados pelas cidades por ser verificado pelo aumento no número de cidades participantes da Rede de Mercocidades, conforme demonstrado no mapa baixo:

Os membros da Rede de Mercocidades são também incentivados a participar de outras redes de cidades, aumentando o escopo de atuação internacional das mesmas. Uma destas redes, denominada Fórum de Autoridades Locais para a Inclusão Social e a Democracia Participativa (Rede FAL), criada a partir do Fórum Social Mundial de Porto Alegre em 2001, incentiva seus membros a intensificar sua atuação internacional para aprimorar a gestão de políticas públicas locais que combatam a exclusão social, apoie o desenvolvimento sustentável, o respeito aos direitos humanos, entre outros. A Rede FAL situa enfaticamente os efeitos adversos da globalização neoliberal como obstrutores da execução de políticas públicas inclusivas e democratizadoras da riqueza e poder.

A Carta do Rio, documento oficial da Rede de Mercocidades, enfatiza a importância do fortalecimento do da integração entre os países do Mercosul. É possível afirmar, a partir da análise dos documentos da Rede de Mercocidades que a organização procura legitimar sua atuação a partir da constante reafirmação dos 
interesses dos países e da região a que pertencem, não transparecendo a priori posicionamentos antagônicos àqueles defendidos pelos países do Mercosul.

Em seu Art. $6^{\circ}$, que regulamenta os princípios direcionadores para associação à Rede, os governos estaduais e/ou provinciais, bem como países associados ao Mercosul são listados como sócios ativos da Rede, desde que eleitos democraticamente, que podem participar das deliberações da Rede de Mercocidades, reafirmando seu caráter agregador ao redor das múltiplas estâncias de governo, e reforçando o conceito de governança local através da multiplicidade de atuação dos diversos atores envolvidos.

A Carta de Porto Alegre, documento criado em 1996, reafirma que as esferas locais devem atuar junto aos governos centrais e estaduais/provinciais como atores efetivos de construção real de participação, bem como na construção de políticas públicas representativas das demandas locais. Ressalta-se no documento a importância de políticas públicas voltadas ao planejamento urbano, saúde e educação, turismo, comércio exterior, entre outros.

Para garantir uma maior efetividade na troca de experiências e atuação nas políticas públicas locais, a Rede de Mercocidades foi estruturada em torno de 14 áreas temáticas, divididas em: Ambiente e Desenvolvimento Sustentável; Autonomia, Gestão e Financiamento Sustentável; Ciência Tecnologia e Capacitação; Cooperação Internacional Descentralizada; Cultura; Esporte; Desenvolvimento Econômico Local (Economia Solidária e Fomento de Negócios); Desenvolvimento Social (Direitos Humanos); Desenvolvimento Urbano; Educação, Gênero e Município; Juventude; Planejamento Estratégico; Segurança Cidadã e Turismo.

As áreas temáticas atuam em projetos que incentivam o desenvolvimento de setores não tradicionais como o turismo, os serviços financeiros e de treinamento, bem como o desenvolvimento da gestão de qualidade; na promoção de pesquisas e debates (técnico e político) sobre os processos de transformação e de descentralização política e administrativa das cidades da região, abrangendo ainda tópicos como os processos de modernização administrativa, as estratégias de participação cidadã, os 
sistemas jurisdicionais, a autonomia e o orçamento municipal. Ainda atuam em novos modelos de gestão de políticas sociais, para compreensão das dimensões sociais da pobreza, buscando estratégias políticas para os grupos vulneráveis, coordenação Interjurisdicional das políticas sociais, entre outros.

A formatação da Rede de Mercocidades é fundamentada na possibilidade de participação ativa e democrática e propõe fortalecer as capacidades dos atores locais (governos e sociedade civil) para a construção de políticas públicas efetivas. Entretanto, faz-se necessário contextualizar a Rede de Mercocidades quanto aos desafios presentes ao funcionamento da rede como instrumento de fato democrático e representativo das cidades latino-americanas. Desta forma, ainda que o número de cidades membro tenha aumento de 16 em 1995 a 272 em 2013 (MERCOCIDADES, 2013), a participação em rede de cidades ainda é localizada entre as cidades de tamanho médio e grande, que já possuem algum tipo de estrutura estabelecida para a promoção de instrumentos e mecanismos de inserção internacional e de melhorias das políticas públicas.

Segundo Batista et al (2008) somente 8\% dos municípios localizados em países do Mercosul fazem parte da Rede de Mercocidades. Apesar do baixo índice de participação dos municípios do Mercosul na Rede de Mercocidades é possível, ainda segundo o autor, perceber um crescimento na participação de governos subnacionais na atuação em redes de cidades. Somando-se somente governos subnacionais da Argentina, Brasil e Peru, são ao todo 770 governos locais participantes de redes de cidades.

O mapa abaixo indica as regiões com maiores concentrações de cidades participantes: 
Figura 1 - Mapa das Mercocidades

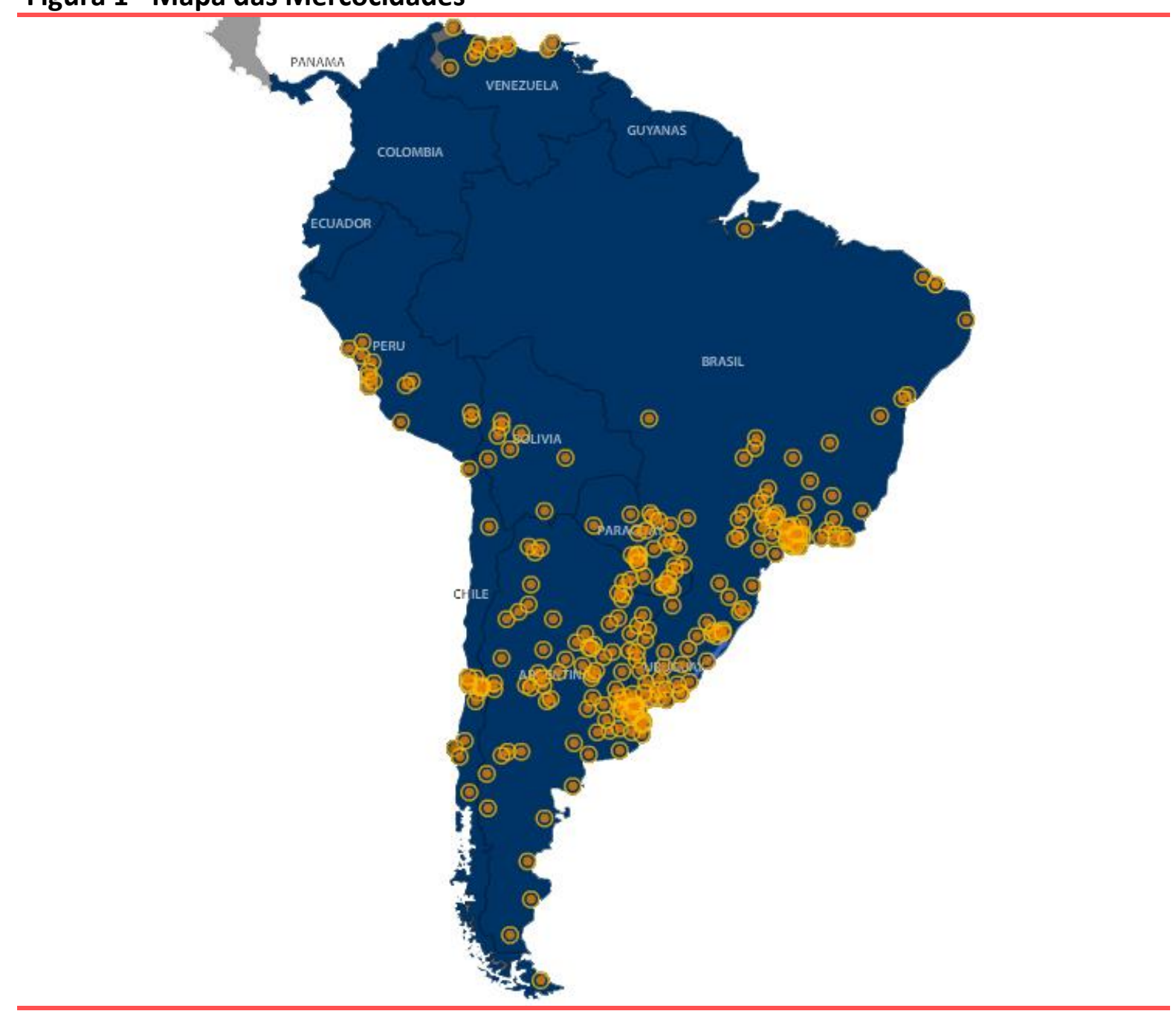

Fonte: Merco Ciudades, (disponível em: http://www.mercociudades.org/pt-br/node/2313)

Neste contexto, é possível afirmar que a formação de redes de cidades ainda é um instrumento de inserção internacional restrito às cidades que já possuem estruturas e organizações orientadas às questões econômicas, políticas e sociais. Entretanto, o potencial de tal instrumento não deve ser desconsiderado em virtude das assimetrias hoje presentes, pois não obstante os desafios apontados, a criação de redes representa um processo de institucionalização e de legitimização das relações internacionais dos entes subnacionais, pois propicia a realização de acordos e 
programas que intensificam a integração regional. No caso da Rede de Mercocidades,

o fato das principais cidades e capitais da região serem membros reforça a legitimidade desta rede, reforçando o potencial de expansão e atração de novos municípios para a atuação em rede.

\section{Considerações finais}

Este artigo procurou analisar exemplos de redes de cidades como instrumento de inserção internacional sob a luz dos princípios de governança local e seus impactos na elaboração de políticas públicas locais. Ainda que existam argumentos que relacionem a ideia de governança como um termo utilizado para encobrir cortes de gastos do governo, e que esconde em sua origem os efeitos das medidas neoliberais de privatização e terceirização dos serviços públicos para agentes do mercado, o conceito de governança aqui explorado indica também uma conceito compreendido positivamente em relação à formação de instituições e processos, bem como formas de organizações envolvendo atores públicos e privados, que visam à satisfação de necessidades e vontades dos cidadãos.

O contexto das cidades contemporâneas, inseridas nos processos de reestruturação produtiva, globalização e neoliberalização política e econômica, impulsionaram a busca por novas formas de governança local, compelidas pela necessidade de capturarem recursos e investimentos externos, complexificando a interação entre atores políticos e econômicos, e compelindo cidades a diversificar seu escopo de atuação para atender a essas demandas e oportunidades. Neste contexto, as cidades intensificam a busca por formas de inserção internacional, sendo as iniciativas de formação de redes de cidades um mecanismo que possibilita o compartilhamento de experiências de governança local e impactam positivamente nas políticas públicas locais.

As redes de cidades se tornam conexões de complementaridade de funções, ou seja, cidades que formam relações horizontais e multicentrais, permitindo aumentar a cooperação econômica que visam melhorar os mais diversos aspectos das políticas 
públicas locais. Ao intensificar sua atuação em organizações internacionais as cidades tornam-se ainda mais relevantes como centros produtores de conhecimento e inovação, desenvolvendo relações de maior complexidade e interdependência entre os diversos atores que coexistem no âmbito municipal e internacional.

\section{Referências bibliográficas}

Aldecoa, Francisco e Keating, Michael. 1999. Paradiplomacy in Action: the foreign relations of subnational governments. New York: Routledge.

Bagnasco, Arnaldo e Le Galés, Patrick. 2000. Cities in Contemporary Europe. Cambridge: University Press.

Batista, Sinoel et al. 2004. Redes De Cidades. Texto elaborado para a Federação Latino Americana de Cidades, Municípios e Associações.

Batten, David F. 1995. Network cities: creative urban agglomerations for the 21st century. Urban Studies. 32.2, March.

Baycan Levent, Tuzin; Kundak, Seda; Gulumser, Aliye Ahu. 2004. The role of "network cities" in construction of global urban culture. $44^{\text {th }}$ European Congress of the European Regional Science Association. Porto, Portugal.

Borja, Jordi e Castells, Manuel. 1997. Local y Global: la gestión de las ciudades en la era de la información. Madri: Taurus Pensamiento.

Brenner, Neil e Theodore, Nik. 2002. Spaces of Neoliberalism. Oxford: Blackwell.

Castells, Manuel. 2005. A Era da Informação: Economia, Sociedade e Cultura. Volume I. A Sociedade em Rede. Fundação Calouste Gulbenkian, 2. a ed., Lisboa.

Deepak, Nayyar (ed.) 2002. Governing Globalization: Issues and Institutions. Oxford: Oxford University Press.

FAMSI - Fundo Andaluz de Municípios para a Solidariedade Internacional. 2011. Nuevas Formas de Gobernabilidad Local: principales desafios de los presupuestos participativos. Novembro. Disponível em: http://www.mercociudades.org/pt-br/node/2113. Acesso em: 16 de novembro de 2012.

Harding, Alan. 1997. Urban regimes in a Europe of cities? In: European urban and regional studies, vol 4 (4), p. 291-314.

Kazepov, Yuri (org.). 2005. Cities of Europe. Oxford: Blackwell. 
Kaul, Inge; Grumberg, Isabelle e Stein, Marc (Eds.). 1999. Global Public Goods: International Cooperation in the 21st century. New York: Oxford University Press.

Leitner, Helga e Sheppard, Eric. 2002. "The City Is Dead, Long Live The Net": Harnessing European Interurban Networks for a Liberal Agenda. In: BRENNER, Neil; Theodore, Nik. Spaces of Neoliberalism. Oxford: Blackwell.

Marks, Gary; Liesbet, Hooghe; Arjan, H. Schakel. 2008. Measuring Regional Authority. In: Regional Federalism and Federal Studies, Vol. 18 (2).

MERCOCIDADES. 2012. Disponível em: http://www.mercociudades.org/pt-br/node/2251 . Acesso em: 16 de novembro.

Milani, Carlos R. S. e Ribeiro, Maria Clotilde Meirelles. 2011. "International relations and the paradiplomacy of Brazilian cities: crafting the concept of local international management" In: BAR, Braz. Adm. Rev. [online], vol.8, n.1, pp. 21-36.

Moreira, Fabiano de Araújo; Senhoras, Elói Martins e Vitte, Claudete de Castro Silva. 2009. Geopolítica da paradiplomacia subnacional: Um estudo sobre a extroversão internacional dos municípios da rede de mercocidades. Apresentado no Anales del XII Encuentro de Geógrafos de América Latina. Montevidéu. Jan.

Rhodes, R.A.W. 1996. The New Governance: Governing without Government. Political Studies, XLIV, 652-667.

Rodrigues, Gilberto et al. 2009. Cidades em Relações Internacionais: análises e experiências brasileiras. São Paulo: Faculdade Santa Marcelina.

Rosenau, James e Czempiel, Ernst-Otto (eds.). 1992. Governance without Government: Order and Change in World Politics. Cambridge: Cambridge University Press.

Salomón, Mónica e Nunes, Carmen. 2007. A ação externa dos governos subnacionais no Brasil: os casos do Rio Grande do Sul e de Porto Alegre. Um estudo comparativo de dois tipos de atores mistos. In: Contexto Internacional [online], vol.29, n.1.

Sassen, Saskia. 1993. A cidade global. In: Lavinas, L. (org.). Reestruturação do espaço urbano e regional no Brasil. São Paulo: Hucitec/Anpur.

Sellers, Jefferey M. e Kwak, Sun-Young. 2011. State and Society in Local Governance: Lessons forma Multilevel Comparison. In: International Journal of Urban and Regional Research, vol. 35.3, May.

Simões, Jorge Manuel Salgado. 2010. Cidades em rede e redes de cidades: o movimento das cidades educadoras. Dissertação de Mestrado em Cidades e Culturas Urbanas, sob orientação do Professor Doutor Carlos José Cândido Guerreiro Fortuna, apresentada à Faculdade de Economia da Universidade de Coimbra.

Stoker, Gerry. 1998. Governance as Theory: Five Propositions. International Social Science Journal, 155: 17-28.

Stoker, Gerry. 2011. Was Local Governance Such a Good Idea? A Global Comparative Perspective. In: Public Administration, vol. 89, No. 1. 
Yahn Filho, Armando Gallo. 2011. Relações internacionais e atores subnacionais: um estudo da inserção internacional da Região Metropolitana de Campinas /Tese de Doutorado apresentada ao Departamento de Ciência Política do Instituto de Filosofia e Ciências Humanas da Universidade Estadual de Campinas, Campinas, SP : [s. n.].

\section{Abstract}

Aspects of local governance: international integration of cities through networks of cities

The processes of economic restructuring, globalization and implementation of the neoliberal agenda occurred in the last decades has increased the debate surrounding the role of the cities in face of greater competition for resources, access to foreign investments, among others aspects. In this context, there is an intensification of international action by cities as a mechanism to improve local governance procedures and standards. The objective of this article is to argue that one mechanism for increasing the international insertion of cities is the formation of networks of cities, which is an instrument for promoting regional integration and improving public policies through the development of programs and agreements. A regional network of cities named Rede de Mercocidades will be presented as case study. Key-words: Governance, globalization, cities network, Rede de Mercocidades.

Tramitação do artigo na revista Submetido: 20/06/2013

Revisões requeridas: 08/09/2013

Versão revista: 30/09/2013

Aceito: 08/10/2013 